\title{
R-Lenses as a Tool for the Enterprise Resilience Analysis
}

\author{
Kozlovsky A.N. ${ }^{1}$ Nedosekin A.O. ${ }^{2, *}$ Abdoulaeva Z.I. ${ }^{3}$ Reyshakhrit E.I. ${ }^{4}$ \\ ${ }^{1}$ Northwest Open Technical University, Russian Federation \\ ${ }^{2} L L C « C-F I N A N C E »$ International Academy of Ecology, Human Security and Nature Sciences (IAELPS), Russian \\ Federation \\ ${ }^{3}$ Peter the Great St.Petersburg Polytechnic University (SPbPU), Russian Federation \\ ${ }^{4}$ Saint-Petersburg Mining University, Russian Federation \\ *Corresponding author. Email: sedok@mail.ru
}

\begin{abstract}
Purpose. To demonstrate a new R-lens tool designed to analyse the economic resilience of enterprises as part of their industry group.

Method. The R-lens is a multidimensional fuzzy parabolic regression that best approximates the set of stable states of the economic system in the selected coordinate space. Parabolic regression parameters are refined in the course of solving the optimization problem with natural restrictions.

Results. R-lenses for five industry groups of industrial enterprises are received: C11, DJ27, DK29, DL31 and E40 (NACE 1.1 coding). As an example, an R-lens is presented for the international metallurgy industry in the coordinates "labour efficiency (LE) - net profitability (NP)".

Conclusion. The effectiveness of using the R-lens tool for the analysis of economic resilience of enterprises is proved.
\end{abstract}

Keywords: resilience, $R$-lens, fuzzy parabolic regression

\section{INTRODUCTION}

The resilience of enterprise economic systems in the report refers to the ability of enterprises to achieve their strategic goals in the face of external challenges of a negative and positive nature [1]

In the practice of analysing the stability of mechanical systems, the tool for distinguishing parametric phase space is well known, within which mechanical systems maintain their stable dynamic equilibrium. It is appropriate to use a similar tool in the analysis of economic systems, we called it a R-lens (from R - resilience).

$\mathrm{R}$-lenses are defined as zones of economic resilience of companies according to the results of group processing of these enterprises within the same industry. Going beyond these zones multiplies the risk of a company losing its current level of sustainability. The main postulate underlying the R-lens tool is as follows. Companies that are in close proximity to each other on the same factor scales are in a stationary state of market equilibrium, when the markets are divided, and the additional investment in competition is no longer justified. Being in such a peculiar "herd", companies contour their own market niche and it is in it that they reach the maximum of their technological and market efficiency. Any exit beyond the "fence" (beyond the boundaries of the lens) indicates that the company has either changed the product or the business model.
Regardless of the expected results of cardinal changes, in a positive or negative sense, we can confidently say that the company will have to develop a new mechanism for adapting to changes. So far, no mechanism has been found, the stability of the enterprise is temporarily reduced, and the more dramatic the changes, the faster and more dramatic the decrease in the level of stability.

In fig. 1 and 2, for example, parabolic R-lenses according to 100 largest corporations in the USA and Russia, respectively, in coordinates \{labor efficiency (LE) - net profitability (NP) \}, in Russian roubles (RUR).

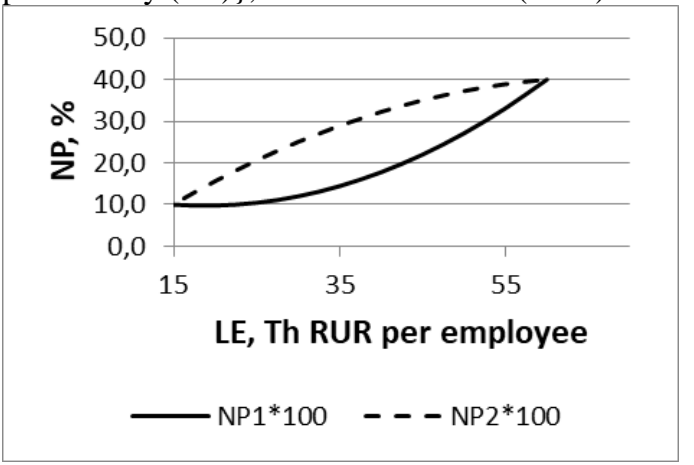

Figure 1. R-lens for the 100 largest US companies

Source: authors own research

It can be seen that the Russian economy is losing the American one both in terms of labor efficiency (excluding the factor of price comparability) and in terms of the level 
of net profitability that is steadily achieved. Moreover, the phase stability zone of the Russian companies is narrower in the width of the lens than the largest US companies.

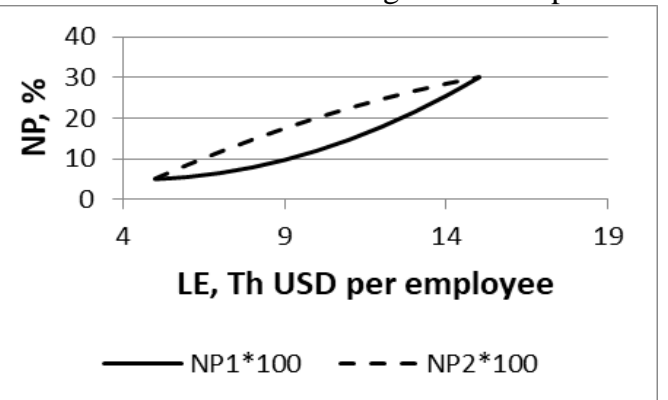

Figure 2. R-lens for the 100 largest companies of the Russian Federation

Source: authors own research

The only similarity is that in both cases LE is the driver of economic success, and this thesis has statistical confirmation (the lens has an angle of inclination to the abscissa axis).

It is appropriate to construct R-lenses as multidimensional fuzzy parabolic regressions. The method of constructing $\mathrm{R}$-lenses is described below.

\section{R-LENSES METHODS}

The technology for building R-lenses has the following main steps:

- we choose a coordinate pair of factors in such a way that it can claim the existence of a nonlinear regression, even if in a fuzzy-logical sense;

- based on the analysis of the dense core of the estimated set of pairs of points, we establish the edges of the lenses significant points through which a nonlinear regression obviously passes. These can be the coordinates of the extreme points of the sample set or characteristic points determined by macroeconomic characteristics. For example, for the Russian case, breakeven in large companies is achieved if LE is not less than RUR 5 Mln revenue excluding VAT per employee per year. Everything below this level is a pronounced anomaly and can be achieved only when the company is located in regions with traditionally low salaries;

- draw two parabolas through 2 selected points - one convex, the other concave - so that the resulting curved lens provides maximum coverage of the data core for the sample, while at the same time preventing the capture of atypical values that make up the visible minority of the sample. The number of points in the lens can act as the objective function of the optimization problem, where the solution is the optimal set of parabolic regression parameters, and the constraints of the problem are natural constraints of the type NP> 0 .

As a result, we get a fuzzy-logical approximation of the sample set, where the regression function is a parabola, the coefficients of which are triangular-fuzzy.
The idea of R-lenses goes back to the idea of areas of non-dominated Pareto alternatives, when points from a lens that are not comparable, however, dominate by the stability criterion any other points below or to the right of the lens, if we are talking about the selected coordinates $\{$ LE - NP $\}$. A typical example of a multitude of nondominated Pareto alternatives and an analogue of the $\mathrm{R}$-lens is the efficient frontier of the investment portfolio when it is introduced into the model in the form of a fuzzy curved strip [2]. Thus, R-lenses should be considered as an instrument for optimizing the industrial portfolio according to the criterion of economic resilience.

\section{RESULTS}

The R-lens tool was used to analyse international industrial companies, distinguished in five industry classes (industry coding is in accordance with the European standard NACE 1.1 [3]: C11 - oil and gas sector; DJ27 metallurgy; DK29 - general engineering; DL31 - electrical engineering; E40 - Electricity and transmission networks 82 companies were analysed, 15-20 companies in each industry.

The technology for collecting and processing data during the analysis was as follows:

- 12 key factors of economic resilience were identified, which are included in 4 analytical blocks: profitability, turnover and leverage, cost of capital, labor efficiency;

- the identified factors were estimated based on the IFRS reporting standard of companies presented on Yahoo Finance [4];

- all the factors evaluated have passed the procedure of linguistic rationing in the sense of Zadeh [5];

- the integrated level of economic sustainability of all companies for 2015 - 2018 was evaluated, according to the two-level technology of the matrix aggregate calculator [6];

- as a detailed example, one of the Russian companies of the selected industry class was considered. It was important to check whether the Russian company fits into the international resilience standards, how they developed in the course of a joint analysis of similar international companies, what discrepancies and weaknesses are seen in the structure of the business of the companies;

- for each industry class, its own set of R-lenses was built. For instance, for the industry DJ27 (metallurgy) company location in $\{\mathrm{LE}-\mathrm{NP}\}$ coordinates is presented in fig. 3 .

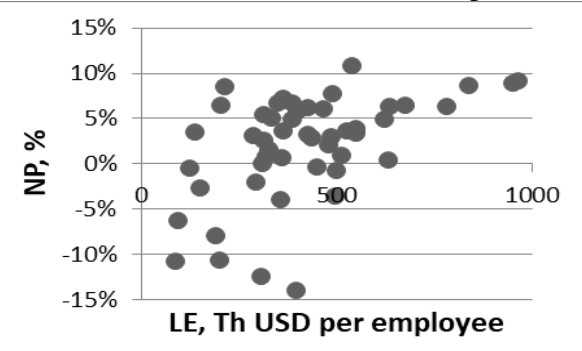

Figure 3 The ratio of LE-NP for companies of class DJ27 
It is clear that points with a negative NP cannot enter the R-lens (the company has temporarily lost resilience); Preliminary analysis of the phase space of Fig. 3 gives the coordinates of four optimal points through which it is possible to conduct a fuzzy-multiple parabolic regression: $(200,2 \%) ;(500,3 \%) ;(500,10 \%) ;(800,12 \%)$. The equations of the lower and upper parabolic lenses bounding the lens are constructed based on the solution of two systems of linear algebraic equations of dimension $3 \times 3$ (by the number of significant points of the parabola) and have the form:

$\mathrm{NP} 1=0.444 * 10-6 * \mathrm{LE}^{2}-2.8 * 10^{-4} * \mathrm{LE}+5.78 * 10^{-2}$

$\mathrm{NP} 2=-0.33 * 10-6 * \mathrm{LE}^{2}+5.0 * 10^{-4} * \mathrm{LE}-6.67 * 10^{-2}$

In fuzzy parabolic regression, the coefficients can be represented both by intervals and triangular fuzzy numbers. For example, in interval recording, the regression looks like this

$\mathrm{NP}=\mathrm{A}^{*} \mathrm{LE}^{2}+\mathrm{B} * \mathrm{LE}+\mathrm{C}$,

where $\mathrm{A}=[0.444,-0.33]^{*} 10^{-6} ; \mathrm{B}=[-2.8,5.0]^{*} 10^{-4}$; $\mathrm{C}=[-5.78,-6.67]^{*} 10^{-2}$

It should be noted that interval numbers $\mathrm{A}$ and $\mathrm{C}$ are mirror intervals (the left edge of the interval is larger than the right). The same mirror fuzzy numbers are well known in fuzzy-logical model descriptions of derivative financial instruments.

The resulting lens is shown in Fig. 4.

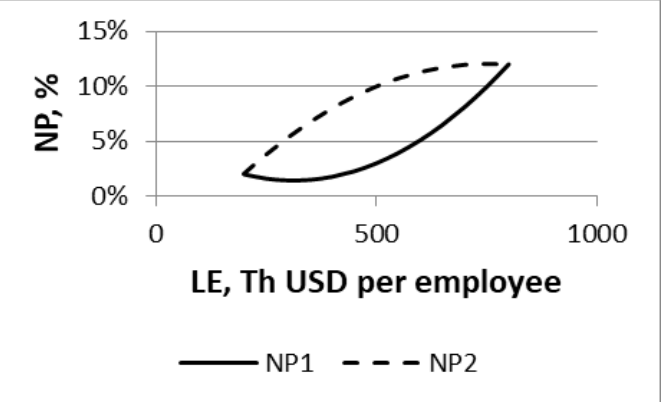

Figure 4. Regression R-lens for DJ27 companies

Based on the results of the review, we can conclude that labor efficiency in the metallurgical sector is a driver of companies' profitability, along with the dynamics of world prices for ferrous and non-ferrous metals. This is a significant difference between, for example, the metallurgical industry and the oil \& gas industry, where everything is decided solely by the hydrocarbon price environment, and there is no regression of the LE-NP. But in our case, LE is clearly a driver of economic resilience.

\section{CONCLUSION}

If a point related to the enterprise falls into the R-lens, it can be considered that the enterprise is stable within the framework of the selected group of criteria and does not contain critical vulnerabilities identified experimentally. It does not follow from this that in the future there will be no such external challenges that will far exceed the ability of industries or regions to resist such challenges. This suggests that the dimensions of R-lenses should be continuously updated in real time. It is also advisable to identify the reasons why certain enterprises do not fit into their industry-specific R-lens, what is the reason for the deviations. For example, a large number of Russian enterprises have low level of LE, which makes them uncompetitive in the world market. Such enterprises are not able to enter the foreign market and easily lose ground in their own market, losing tenders at tenders at a price to foreign competitors. This is a sure sign that the resilience of the enterprise to market fluctuations is lost and needs to be restored.

\section{REFERENCES}

[1] A.O. Nedosekin, E.I. Reishahrit, A.N. Kozlovsky Strategic approach to assessing economic sustainability objects of mineral sector of Russia, Zapiski Gornogo Instituta. Vol. 237. P.p. 354-360. 2019, DOI: https://doi.org/10.31897/PMI.2019.3.354

[2] A.O. Nedosekin, Financial management using fuzzy sets. Moscow, Audit \& Finance analysis, 2003, 195 p.

[3] NACE 1.1. RAMON - Reference and Management of Nomenclatures, 2020, URL: https://ec.europa.eu/eurostat/ramon/nomenclatures/inde x.cfm?TargetUrl=LST_CLS_DLD\&StrNom=NACE_1 1 last accessed 2020/01/20

[4] Yahoo Finance portal (2020). URL: https://finance.yahoo.com/ last accessed 2020/01/20L.

[5] Zadeh, J. Kasprzyk, Fuzzy logic for the management of uncertainty. Wiley, NY, US, 1992, 676 p. ISBN-13: 978-0471547990

[6] Z.I. Abdoulaeva, D.F Kurbanbaeva, M.E. Topuzov, Application of the matrix aggregate calculator (MAC) for forecasting disease recommendation. In: Shaposhnikov, S. (eds) Proceedings of International Conference on Soft Computing and Measurements, SCM 2017, pp. 684-685. IEEE, Saint-Petersburg, Russia, 2017.2 DOI: https://doi.org/10.1109/SCM.2017.7970689

[7] E.A. Konnikov, O.A. Konnikova, D.S. Negashev, A.V. Novikova, Sustainability of development of industrial enterprises depending on the level of their manufacturability. Proceedings of the 32nd international business information management association conference (IBIMA), 2018, pp. 4431-4444. ISBN: 978-0-9998551-1-9 